\title{
Pengembangan Media Apron Sistem Pencernaan Manusia untuk Siswa Tunarungu
}

\author{
Uswatun Khasanah ${ }^{1}$, Ahmad Samawi ${ }^{2}$ \\ ${ }^{1}$ SLB Idayu 3 Malang \\ ${ }^{2}$ Universitas Negeri Malang \\ Email: uswatan22khasanah@yahoo.com
}

\begin{abstract}
Abstrak :Hasil observasi tentang pembelajaran IPA kelas VIII SMPLB, materi paling sulit dipahami adalah sistem pencernaan, dikarenakan guru memiliki keterbatasan media. Tujuan penelitian menghasilkan produk media Apron Sistem Pencernaan Manusia untuk siswa tunarungu kelas VIII SMPLB. Penelitian menggunakan metode pengembangan model Borg and Gall. Data yang digunakan kualitatif dan kuantitatif. Pengumpulan data menggunakan angket dan tes. Teknik analisis data meliputi deskriptif kualitatif dan kuantitatif. Hasil penelitian menunjukkan media layak digunakan siswa tunarungu kelas VIII SMPLB. Kesimpulan dari penelitian media Apron Sistem Pencernaan Manusia berhasil dikembangkan. Saran bagi guru dianjurkan menggunakan media apron, bagi peneliti selanjutnya disarankan mengembangkan media pada materi lain.
\end{abstract}

Kata Kunci: tunarungu, media, apron sistem pencernaan manusia

\begin{abstract}
From the observations of science teaching in class VIII SMPLB, the material most difficult to understand is the digestive system. That is because teachers have limited media. The purpose of this research and development was to produce products an Apron media of Human Digestive System for students with hearing impairment class VIII in SMPLB. This research method was adapted from Borg and Gall development model. The type of data was obtained by the qualitative and quantitative data. The collection of data was obtained using questionnaires and tests. Data analysis techniques was including qualitative and quantitative descriptive analysis. The result of this research was media well-used for students with hearing impairment of class VIII in SMPLB. The conclusion of this study media Apron Human Digestive System for deaf students of class VIII SMPLB has been successfully developed. Suggestions for teachers are encouraged to use apron media, for further research is suggested to develop media on other materials.
\end{abstract}

Keywords: Hearing impairment, media, apron of digestive system

Pendidikan adalah salah satu hak dasar warga negara. Negara telah mengatur hal ini dalam Undang-Undang Nomor 20 Tahun 2003, pada pasal 5 Ayat 1 dan 2 yang berbunyi: (1) "setiap warga negara mempunyai hak yang sama untuk memperoleh pendidikan yang bermutu, (2) "warga negara yang memiliki kelainan fisik, emosional, mental, intelektual, dan/atau sosial berhak memperoleh pendidikan khusus". Anak tunarungu adalah anak yang mengalami gangguan dalam pendengaran, baik permanen maupun tidak permanen yang disebabkan karena tidak berfungsinya satu atau lebih organ telinga bagian luar, tengah, dan dalam yang disebabkan oleh penyakit, kecelakaan, atau sebab lainnya sehingga membutuhkan pelayanan pendidikan khusus.

Dari hasil observasi tentang pembelajaran IPA, materi yang paling sulit dipahami oleh siswa yang berkaitan dengan IPA adalah materi tentang sistem pencernaan manusia. Guru kesulitan menyampaikan materi tentang sistem pencernaan manusia secara keseluruhan, karena guru memiliki keterbatasan media. Selama ini materi sistem pencernaan manusia disampaikan menggunakan media gambar dan boneka torso (boneka organ tubuh manusia). Media tersebut masih tidak efektif digunakan dalam pembelajaran materi sistem pencernaan manusia karena media gambar cenderung monoton sehingga membuat anak bosan.

Untuk itu dibutuhkan media yang dapat membantu anak tunarungu dalam mempelajari konsep sistem pencernaan manusia secara kesuluruhan meliputi organ pencernaan, fungsi organ pencernaan, dan penyakit pencernaan sesuai dengan Kompetensi Dasar yang ada pada kurikulum. Media tersebut adalah media yang memiliki kelebihan diantaranya: (1) tidak hanya dapat diamati secara klasikal, tetapi bisa digunakan secara individu dan berpasangan, (2) mudah dibawa kemana-mana, (3) ringan, (4) tahan lama, (5) dan dapat digunakan untuk mempelajari mated sistem pencernaan manusia secara keseluruhan.

Berdasarkan hasil observasi dan beberapa temuan penelitian sebelumnya, peneliti ingin mengembangkan media pembelajaran apron untuk siswa tunarungu pada materi sistem pencernaan manusia dengan mempertimbangkan berdasarkan pada kebutuhan anak. Media tersebut diharapkan lebih efektif dan efisien ketika digunakan oleh siswa tunarungu. Oleh karena itu peneliti mengambil judul "Pengembangan Media Apron Sistem Pencernaan Manusia untuk Siswa. 
Tabel 1 Hasil Validasi Ahli dan Kualifikasi Keberhasilan Media

\begin{tabular}{|c|c|c|c|c|}
\hline NO. & Validator & Skor & $\begin{array}{l}\text { Kuaiiti- } \\
\text { kasi }\end{array}$ & $\begin{array}{l}\text { Keteran- } \\
\text { gan }\end{array}$ \\
\hline 1 & $\begin{array}{l}\text { Ahli Me- } \\
\text { dia }\end{array}$ & 99 & $\begin{array}{l}\text { Sangat } \\
\text { Valid }\end{array}$ & $\begin{array}{l}\text { Sangat baik } \\
\text { digunakan }\end{array}$ \\
\hline 2 & $\begin{array}{l}\text { Ahli Ma- } \\
\text { teri }\end{array}$ & 62 & Valid & $\begin{array}{l}\text { Boleh digu- } \\
\text { nakan den- } \\
\text { gan revisi } \\
\text { kecil. }\end{array}$ \\
\hline 3 & Praktisi & 66 & Valid & $\begin{array}{l}\text { Boleh digu- } \\
\text { nakan den- } \\
\text { gan revisi } \\
\text { kecil. }\end{array}$ \\
\hline
\end{tabular}

Tabel 2 Hasil Penilaian Angket dan KtilffllfiK88' Keberhasilan Media

\begin{tabular}{|c|c|c|c|c|}
\hline No & Uji Coba & Skor & Kualifikasi & Keterangan \\
\hline 1 & Produk & 103 & $\begin{array}{l}\text { Sangat } \\
\text { Valid }\end{array}$ & $\begin{array}{l}\text { Sangat baik } \\
\text { digunakan }\end{array}$ \\
\hline \multirow[t]{2}{*}{2} & Pemakaian & 99,5 & $\begin{array}{l}\text { Sangat } \\
\text { Valid }\end{array}$ & $\begin{array}{l}\text { Sangat baik } \\
\text { digunakan }\end{array}$ \\
\hline & Rata-Rata & $\begin{array}{l}101 \\
, 25\end{array}$ & $\begin{array}{l}\text { Sangat } \\
\text { Valid }\end{array}$ & $\begin{array}{l}\text { Sangat } \\
\text { Layak }\end{array}$ \\
\hline
\end{tabular}

Pembelajaran IPA untuk anak tunarungu sangat bergantung pada penggunaan media pembelajaran secara visual untuk pencapaian standar minimal proses pembelajaran. Jika indera pendengaran tidak berfungsi, maka anak tunarungu akan mengalami kesulitan dalam memahami pelajaran secara verbal. Oleh karena itu, keberadaan media pembelajaran secara visual akan mempermudah siswa tunarungu dalam memahami pelajaran IPA. Tidak berfungsinya indera pendengaran dengan baik menyebabkan minimnya penguasaan kosa kata dan kemampuan berbahasa. Hal ini menyebabkan anak tunarungu sulit menerima dan memahami informasi baru secara verbal".

Hasil observasi tentang pembelajaran IPA menunjukkan bahwa materi yang paling sulit dipahami oleh siswa tunarungu yang berkaitan dengan pembelajaran IPA adalah materi tentang sistem pencernaan manusia. Guru mengalami kesulitan dalam menyampaikan materi tentang sistem pencernaan manusia secara keseluruhan karena keterbatasan media dalam pembelajaran.

\section{METODE}

Penelitian ini menggunakan model penelitian dan pengembangan prosedural. Model pengembangan merupakan dasar yang digunakan untuk pegembangan produk yang akan dihasilkan (Pradipta, 2017). Dasar dalam pengembangan media ini adalah model pengembangan dari Borg and Gall yang didaptasi oleh Sugiyono (2013) yang terdiri dari 9 langkah pengembangan yaitu: (1) pptensi Masalah, (2) pengumpulan data, (3) desain produk, (4) validasi desain, (5) revisi desain, (6) uji coba produk, (7) revisi produk, (8) uji coba pemakaian (9) revisi produk. Subjek dari penelitian ini adalah siswa tunarungu kelas VIII SMPLB. Data yang digunakan dalam penilitian ini adalah data kualitatif dan kuantitatif. Pengumpulan data menggunakan angket dan tes. Teknik analisis data meliputi analisis deskriptif kualitatif dan kuantitatif.

\section{HASIL DAN PEMBAHASAN}

\section{Hasil}

Penyajian data uji coba diperoleh dari: (1) data hasil validasi ahli, (2) data hasil uji coba produk, dan (3) data hasil uji coba pemakaian. Data yang disajikan diperoleh melalui penilaian validator pada validasi ahli media, ahli materi, dan praktisi. Validasi ahli media dilakukan oleh 1 orang dosen ahli media, validasi ahli materi dilakukan oleh 1 orang dosen ahli di bidang anatomi dan fisiologi, dan validasi praktisi dilakukan oleh 1 orang guru kelas VIII. Pada tahap validasi, diperpleh data kuantitatif dan kualitatif. Data kuantitatif diperoleh dari hasil penilaian yang disajikan pada lembar validasi media, sedangkan data kualitatif diperoleh berdasarkan komentar dan saran terhadap media. Hasil analisis data dari validator disajikan pada tabel 1 dibawah ini.

Merujuk pada tabel 1 di atas, dapat disimpulkan bahwa media valid dan layak digunakan untuk siswa tunarungu kelas VIII SMLB. Hal tersebut dapat dilihat dari hasil validasi ahli media yang mendapatkan total skpr 99 (sangat valid), ahli materi mendapatkan skor 62 (valid), dan praktisi mendapatkan skor 66 (valid).

Selain data kuantitatif yang diperoleh dari validasi ahli dan praktisi, juga didapatkan data kualitatif berupa komentar maupun saran dari para ahli serta praktisi. Dari ahli media perlu dilakukan perbaikan dari desain kartu yaitu perbaikan dari pemilihan jenis huruf (font) dan ukuran spasi. Selain itu ahli media juga memberikan saran untuk pendamping atau pengajar seharusnya melakukan pembelajaran yang kreatif dalam menggunakan media apron tersebut Dari ahli materi perlu perbaikan pada gambar penyakit amandel dan perbaikan pada kalimat fungsi lambung. Dan untuk praktisi secara keseluruhan media sudah cukup bagus untuk digunakan, namun untuk kedalaman isi atau materi tergantung pada individu karena setiap anak memiliki tingkat penguasaan materi dan tingkat IQ yang berbeda-beda. 
Tabel 3 Hasil Analisis Validitas Gabungan

\begin{tabular}{|c|c|c|c|}
\hline No. & Validitas & Skor & Kualifikasi \\
\hline 1 & Ahli Media & 99,00 & $\begin{array}{l}\text { Sangat Valid, } \\
\text { sangat efektif, } \\
\text { sangat tuntas, } \\
\text { dapat digunakan } \\
\text { tanpa perbaikan. }\end{array}$ \\
\hline 2 & Ahli Materi & 77,50 & $\begin{array}{l}\text { Cukup valid, } \\
\text { cukup efektif, cu- } \\
\text { kup tuntas, dapat } \\
\text { digunakan } \\
\text { dengan perbaikan } \\
\text { kecil }\end{array}$ \\
\hline 3 & Praktisi & 78,57 & $\begin{array}{l}\text { Cukup valid, } \\
\text { cukup efektif, cu- } \\
\text { kup tuntas, dapat } \\
\text { digunakan } \\
\text { dengan perbaikan } \\
\text { kecil. }\end{array}$ \\
\hline 4 & $\begin{array}{l}\text { Uji Coba } \\
\text { Produk }\end{array}$ & 88,79 & $\begin{array}{l}\text { Sangat Valid, } \\
\text { sangat efektif, san- } \\
\text { gat tuntas, dapat } \\
\text { digunakan } \\
\text { tanpa perbaikan }\end{array}$ \\
\hline 5 & $\begin{array}{l}\text { Uji Coba } \\
\text { Pem }\end{array}$ & 76,25 & $\begin{array}{l}\text { Cukup valid, } \\
\text { cukup . Sangat } \\
\text { valid, sangat efek- } \\
\text { tifi, sangat tuntas, } \\
\text { dapat digunakan } \\
\text { tanpa perbaikan. }\end{array}$ \\
\hline & Rata-Rata & $84,02 \%$ & \\
\hline
\end{tabular}

Selama proses uji coba yang meliputi uji coba produk dan uji coba pemakaian, guru melakukan penilaian terhadap media menggunakan angket penilaian media yang telah disediakan oleh peneliti. Data yang diperoleh dari angket berupa data kuantitatif dan kualitatif. Data kuantitatif basil penilaian angket dapat dilihat pada tabel 2 .

Berdasarkan tabel 2, secara umum media basil pengembangan memperoleh skor rata-rata 101,25 (sangat valid), sehingga media sangat layak untuk digunakan dalam pempelajaran pada siswa tunarungu kelas VIII SMPLB. Setelah melakukan uji coba, didapatkan basil bahwa media Apron Sistem Pencernaan Manusia layak untuk digunakan siswa tunarungu kelas VIII SMPLB. Selain dari basil penilaian angket oleh guru, juga didapatkan data kualitatif yang berupa komentar/saran yang akan dijadikan sebagai dasar dalam perbaikan media. Dari komentar/saran tersebut dapat diketahui keterbatasan/ kekurang media dan saran perbaikan media tersebut.

Dari hasil uji coba produk didapatkan keterbatasan media adalah (1) kalimat pada kartu fungsi organ perlu dijelaskan kepada siswa dengan detail sebelum siswa menggunakan media, karena pada saat uji coba produk siswa masih mengalami kesulitan dalam memahami kalimat pada kartu, baik pada kartu fungsi maupun kartu penyakit, (2) penyederhanaan kalimat pada fungsi usus halus yang sebelumnya "menyerap nutrisi dan vitamin pada makanan" menjadi "meneyerap nutrisi dan vitamin", (3) dan penyederhanaan kalimat pada fungsi usus besar yang sebelumnya "menyerap air dan mineral dari sisa makanan" menjadi "menyerap air dan mineral".

Sedangkan untuk hasil uji coba pemakaian didapatkan bahwa perlu dilakukan perbaikan pada gambar organ, dimana siswa masih kesulitan untuk membedakan antara usus halus dan usus besar dikarenakan tidak ada pembatas warna. Oleh karena itu perlu dilakukan perbaikan dengan memberikan warna pembatas yang jelas antara usus halus dan usus besar. Untuk memperoleh kesimpulan yang lebih mantap dilakukan analisis validitas gabungan. Hasil analisis validitas gabungan dapat dilihat pada tabel 3 .

Dilihat dari label 3 di atas dapat diketahui jika media apron yang dikembangkan memperoleh hasil sangat valid, dengan demikian dapat disimpulkan bahwa media Apron Sistem Pencernaan Manusia sangat layak digunakan untuk siswa tunarungu kelas VIIISMPLB.

\section{Pembahasan}

Anak tunarungu yang mengalami kekurangan pada indera pendengaran membutuhkan suatu media pembelajaran yang lebih mengarah pada aspek visual. Berdasarkan pada pengertian dasar media yang berasal dari Bahasa Latin medius yang secara harfiah berarti 'tengah', 'perantara', atau 'pengantar'. Secara sederhana media dapat diartikan sebagai perantara dalam proses pembelajaran. Menurut Arsyad (2014: 3) "media yang membawa pesan-pesan atau informasi yang bertujuan intruksional atau mengandung maksudmaksud pengajaran".

Menurut Musfiqon (2011) "secara utuh media pembelajaran dapat didefinisikan sebagai alat bantu berupa fisik maupun non fisik yang sengaja digunakan sebagai perantara antara guru dan siswa dalam memahami materi pembelajaran agar lebih efektif dan efisien". Dari beberapa definisi ahli tersebut, peneliiti menyimpulkan bahwa media pembelajaran adalah alat bantu fisik maupun non fisik yang digunakan untuk menyampaikan isi materi yang membawa informasi tentang materi pembelajaran agar proses belajar mengajar berjalan lebih efektif dan efisien.

Dalam mengembangkan sebuah media pembelajaran harus didasarkan pada fungsi penggunaan media pembelajaran untuk menghasilkan 
media yang baik. Levie \& Lentz dalam Arsyad (2013) mengemukakan empat fungsi media pembelajaran, khususnya media visual yaitu (1) fungsi atensi media visual merupakan inti, yaitu menarik dan mengarahkan perhatian siswa untuk berkonsentrasi kepada pelajaran yang berkaitan dengan makna visual, (2) fungsi afektif, gambar atau lambang visual dapat menggugah emosi dan sikap siswa, (3) fungsi kognitif, lambang visual atau gambar dapat memperlancar pencapaian tujuan untuk memahami dan mengingat informasi atau pesan yang terkandung dalam gambar, (4) dan yang terakhir adalah fungsi kompensatoris, media visual berfungsi untuk mengakomodasikan siswa yang lemah, lambat menerima, dan memahami isi pelajaran yang disajikan dengan teks atau disajikan secara verbal.

Selain memperhatikan dari fungsi media pembelajaran, dalam mengembangkan media pembelajaran juga harus diperhatikan kriteriakriteria dalam memilih media pembelajaran. Menurut Sudjana dan Rival (2009; 4-5) dalam memilih media pembelajaran harus memperhatikan hal-hal diantarnya (1) ketepatan dengan tujuan pengajaran, (2) dukungan terhadap isi bahan pelajaran, (3) kemudahan memperoleh media, (4) ketrampilan guru dalam menggunakan media, (5) tersedia waktu untuk menggunakannya, sehingga media tersebut dapat bermanfaat bagi siswa selama pengajaran berlangsung, (6) Sesuai dengan taraf berpikir siswa, memilih media harus sesuai dengan taraf berpikir siswa, sehingga makna yang terkandung di dalamnya dapat dipahami oleh siswa.

Media Apron Sistem Pencernaan Manusia yang telah dikembangkan memiliki dampak positif terhadap masalah kesulitan siswa tunarungu kelas VIII SMPLB pada materi sistem pencernaan manusia. Dari hasil validasi oleh ahli dan praktisi didapatkan hasil bahwa media apron yang dikembangkan layak digunakan untuk siswa tunarungu kelas VIII SMPLB. Selain itu dari hasil uji coba yang telah dilakukan baik pada uji coba produk maupun pada uji coba pemakaian didapatkan hasil jika media apron efektif digunakan untuk siswa tunarungu kelas VIII SMPLB.

\section{KESIMPULAN DAN SARAN}

\section{Kesimpulan}

Kesimpulan dari penelitian dan pengembangan ini adalah Media Apron Sistem Pencernaan Manusia telah berhasil dikembangkan dan telah dinyatakan valid oleh ahli media, ahli materi, dan praktisi, serta layak digunakan oleh siswa tunarungu kelas VIII SMPLB berdasarkan hasil uji coba produk dan uji coba pemakaian.

\section{Saran}

Peneliti penyarankan pada guru kelas untuk menggunakan media Apron Sistem Pencernaan Manusia pada materi sistem pencernaan manusia, karena media tersebut telah dinyatakan layak digunakan untuk siswa tunarungu kelas VIII SMPLB berdasarkan hasil validasi ahli dan praktisi, serta dari hasil uji coba.

\section{DAFTAR RUJUKAN}

Aditama. S \& Nana. (2016). Penilaian Hasil Proses Belajar Mengajar. Bandung: PT. Remaja Rosdakarya.

Azhar, A. (2014). Media Pembelajaran. Jakarta: PT. Rajagrafmdo Persada.

Efendi, M.(2006). Pengantar Psikopendagogik Anak Berkelainan. Jakarta: PT. Bumi Aksara.2006).

Musfiqon. (2012). Media \& Sumber Pembelajaran. Jakarta: PT. Prestasi Pustakarya.

Narbuko \& Achmadi. (2012). Metodologi Peneltian. Jakarta.- PT. Bumi Aksara.

Pearce, E. (2010). Anatomi dan Fisiologi untuk Paramedis. Jakarta: PT. Gramedia Pustaka Utama Reni. 2013. Teori APD. (Online), (http://renirs. blogspot.co.id/2013/05/teori-aod 7769.htmD. diakses 25 Maret 2016. Soemantri, Sujihati. 2012. Psikologi Anak Luar Biasa. Bandung: PT. Refika.

Pradipta, R. F., \& Andajani, S. J. (2017). Motion Development Program for Parents of Child with Cerebral Palsy. Jurnal Penelitian dan Pengembangan Pendidikan Luar Biasa, 4(2).

Sudjana \& Rivai (2010). Media Pengajaran, Bandung: Sinar Baru Algensindo.

Sugiyono. (2013). Metode Penelitian Pendidikan. Bandung: Alfabeta.

Susilana, R \& Riyana, C. (2009). Media Pembelajaran. Bandung: CV Wacana Prima. Google book, (Online), (https://books.google. co.id/books? id $=$ vqHAwAAOBAJ\&printsec $=$ rrontcover\&hl:=id\&source $=$ gbs ge summary $\mathrm{r} \& \mathrm{cad}=0 \# \mathrm{v}=$ onepage $\& \mathrm{q} \& \mathrm{f}=$ false $\backslash$ diakses 30 April 2016 